\title{
Allergic rhinitis, allergic contact dermatitis and disease comorbidity belong to separate entities with distinct composition of T-cell subsets, cytokines, immunoglobulins and autoantibodies
}

Wenjia Chai ${ }^{1,2+}$, Xuyi Zhang ${ }^{3 \dagger}$, Meixiong Lin ${ }^{3}$, Zhuo Chen ${ }^{3}$, Xiaolin Wang ${ }^{1,2}$, Changqing Wang $^{4}$, Aoyan Chen ${ }^{4}$, Caisheng Wang ${ }^{4}$, Hongwu Wang ${ }^{4^{*}}$, Honghong Yue ${ }^{3,4^{*}}$ and Jingang Gui ${ }^{1,2^{*}}$

\begin{abstract}
Background: Allergic rhinitis (AR) and allergic contact dermatitis (ACD) are prevalent allergic diseases and have significant impacts on patients' daily life. Despite many studies on AR or ACD have been conducted separately, little is known about the immune responses in patients of AR combined with ACD and the interplay between AR and ACD. Our study compared various aspects of immune elements in patients with AR or/and $A C D$, aiming to characterize the immune responses in $A R, A C D$, and $A R$ combined with $A C D$.

Methods: A total of 57 patients diagnosed with AR or/and ACD and 28 healthy volunteers were included. AR patients were further divided into seasonal $A R(S A R)$ and perennial AR (PAR). All subjects' blood samples were taken to assess the concentration of immunoglobulins, complement C3, C4, autoantibodies and cytokines in serum by immunoturbidimetry, ELISA or Luminex200 platform. Peripheral blood mononuclear cells (PBMCs) were subjected to the analysis of lymphocyte subpopulations by flow cytometry.

Results: It indicated that AR disease caused elevated levels of $\lg E$, IgA, IgG, IgG4, as well as IL-4, IL-15, IL-8 and IL-6 in serum. AR patients possessed a decreased CD4/CD8 ratio and an increased proportion of memory CD4+T-cell subset, with a skewed Th2 response and an enhanced CD8 + T-cell activation. Compared with patients with sole AR or $A C D$ condition, $A R+A C D$ patients presented with a significantly increased proportion of memory CD8 + T-cell subset and were prone to autoimmune disorders as indicated by the increased autoantibodies. The immune elements
\end{abstract}

\footnotetext{
*Correspondence: 3349820486@qq.com; cctv201166@126.com; guijingang@bch.com.cn

tWenjia Chai and Xuyi Zhang contributed equally

${ }^{1}$ Laboratory of Tumor Immunology, Beijing Pediatric Research Institute,

Beijing Children's Hospital, Capital Medical University, National Center for Children's Health, Beijing 100045, China

${ }^{3}$ Third Medical Center of Chinese, PLA General Hospital, Beijing 100000,

China

${ }^{4}$ Department of Allergy, Inner Mongolia Xilinguo League Central Hospital, Xilinhot 026000, China

Full list of author information is available at the end of the article
}

(c) The Author(s) 2022. Open Access This article is licensed under a Creative Commons Attribution 4.0 International License, which permits use, sharing, adaptation, distribution and reproduction in any medium or format, as long as you give appropriate credit to the original author(s) and the source, provide a link to the Creative Commons licence, and indicate if changes were made. The images or other third party material in this article are included in the article's Creative Commons licence, unless indicated otherwise in a credit line to the material. If material is not included in the article's Creative Commons licence and your intended use is not permitted by statutory regulation or exceeds the permitted use, you will need to obtain permission directly from the copyright holder. To view a copy of this licence, visit http://creativecommons.org/licenses/by/4.0/. The Creative Commons Public Domain Dedication waiver (http://creativeco mmons.org/publicdomain/zero/1.0/) applies to the data made available in this article, unless otherwise stated in a credit line to the data. 
in patients with ACD only were least affected compared with those in other conditions. Additionally, seasonal or perennial AR patients exhibited different cytokine profiles and proportions of memory T-cell subsets.

Conclusions: In this study, we illuminated the respective characteristics of immune responses in $A R$, ACD, and AR combined with ACD. Meanwhile, we discovered that the PAR and SAR patients possessed different cytokine profiles and T-cell compartments. It suggested that these allergic conditions belong to different disease entities. Characterizing the detailed immune changes in these allergic diseases would help to develop proper treatments targeting particular immune elements in different allergic diseases.

Keywords: Allergic rhinitis, Allergic contact dermatitis, Immune responses, T cells, Cytokines, Autoantibodies

\section{Background}

Allergic rhinitis (AR) and allergic contact dermatitis (ACD) are common allergic diseases worldwide characteristic of high $\operatorname{IgE}$ and allergic inflammation readily triggered by allergens $[1,2]$. AR is the most prevalent mucosal inflammation condition generally manifested with sneezing, nasal congestion, nasal itching and rhinorrhea [1]. It is believed that AR is closely related to the inhaled allergen, while ACD is directly connected with skin exposure [2]. Clinical presentations of ACD in acute phase include pruritus, dryness, erythema and scaling. It can develop into chronic inflammatory conditions upon continuous allergen exposure, and the exact mechanism remains unknown $[3,4]$. The diagnoses of $\mathrm{AR}$ and $\mathrm{ACD}$ mainly depend on the occurrence history, regular clinical laboratory tests, skin prick tests and epicutaneous patch tests [2,5]. Avoidance of allergens is one of the crucial measures for restraining atopic conditions of AR and ACD. While traditional drugs such as antihistamines and corticosteroids can relieve the symptoms, there is no known cure with only the allergen-specific immunotherapy (AIT) lighting a hope for complete remission [2, 6]. AR and ACD seriously influence patients' life quality and bring economic burden to patients and society [7]. Therefore, it is meaningful to investigate the exact immunological characteristics and the differences between AR and ACD, and to explore the mutual interplay between them when patients are inflicted with AR together with ACD.

$\mathrm{AR}$ is an IgE-mediated type I hypersensitivity process that involves several types of immune cells and cytokines $[8,9]$. Depending on its sensitization to cyclic pollens or year-round allergens, AR has been classified as seasonal allergic rhinitis (SAR) or perennial allergic rhinitis (PAR) [1]. Symptoms of AR are triggered by allergens, and antigen-specific IgE is produced as a result of complex interactions between dendritic cells, B cells, T cells, mast cells, and basophils $[9,10]$. Along with antigen presentation and Th2 polarization of $\mathrm{T}$ cells, several critical cytokines such as IL-4, IL-5 and IL-13 are produced [11]. The allergen-specific Th2 response subsequently induces B-cell differentiation and class-switch towards IgE-producing plasma cells mediating inflammatory responses [11, 12]. Further studies demonstrated that in nasal secretions, various cytokines including IL-4, IL-1, IL-2, IL-6, GM-CSF and TNF- $\alpha$ were implicated in AR development and progress $[13,14]$. In addition, Treg cells, characterized by the production of anti-inflammatory cytokines such as IL-10 and TGF- $\beta$, are likely to be important in the control and resolution of AR [15-17]. There is a growing appreciation that $A R$ is not only a disease restricted to nasal passages, but also a manifestation of systemic airway disease [6]. It will be meaningful to investigate the immune process in peripheral blood in addition to nasal secretions.

By contrast, ACD is a delayed type IV hypersensitivity reaction resulting from the activation of allergenspecific T cells [18]. ACD occurs in the dermis and epidermis, where specific $\mathrm{T}$ cells are activated by hapten and an inflammatory cascade is triggered [18]. In light of the knowledge from studies on AR and ACD, it has been accepted that they share similarities of many aspects in their pathogenesis and immune responses. For instance, their allergic inflammatory presentations are driven by multiple immune pathways, especially T-cell mediated immunity $[19,20]$. Nevertheless, it remains elusive whether AR would march faster or become worse from the immunological perspective when ACD is accompanied, or vice versa. In other words, it is not known yet if these two conditions would interplay and reshape the immune response reciprocally, or they merely belong to two independent entities. Through dissecting various immune features of patients with AR/ ACD only or AR concomitant with ACD, our study aims to find the clue to the relationship, if any, between these two highly frequent atopic conditions.

\section{Methods}

\section{Patients}

The present study recruited 57 patients diagnosed with $\mathrm{AR}$ and/or ACD and 28 healthy volunteers aged from 19 to 35 years. The information of the patients and healthy 
controls was displayed in Table 1. All subjects, including healthy volunteers, were subjected to skin prick tests and epicutaneous patch tests. Diagnosis of AR was based on medical history, clinical laboratory findings and skin prick tests according to ARIA guidelines [5]. Based on the results from skin prick tests on cyclic pollens or year-round allergens (summarized in Table 2), AR patients were divided into SAR or PAR. Diagnosis of ACD was made according to medical history, physical examination and confirmed by the epicutaneous patch tests. AR combined with ACD patients were defined as the AR + ACD group. The study was approved by the Medical Ethics Committee of Third Medical Center of Chinese PLA General Hospital and Inner Mongolia Xilinguo League Central Hospital. Written consents were provided by all participants.

\section{Skin prick test and epicutaneous patch tests}

Skin prick tests were performed for the common inhalant allergens in China, including dust mite (Dermatophagoides. pteronyssionus, Dermatophagoides. farinae), trees pollen (Common silver birch, Mountain juniper), and weeds pollen (Mugwort, Japanese Hop). All extracts were prepared from the Allergen Manufacturing and Research Center (Peking Union Medical College Hospital, Beijing, China). Histamine phosphate $(0.01 \mathrm{mg} /$ $\mathrm{ml}$ ) was used as the positive control, and an allergen diluent (normal saline solution) as the negative control. The results were evaluated $15 \mathrm{~min}$ after application. A wheal diameter $\geq 5 \mathrm{~mm}$ after subtracting the negative

Table 1 Patient information

\begin{tabular}{lll}
\hline Group & Gender (female/male, $\boldsymbol{n})$ & Age (years \pm SEM) \\
\hline$H C(n=28)$ & $12 / 16$ & $25.57 \pm 1.01$ \\
$A R(n=30)$ & $12 / 18$ & $27.93 \pm 0.8$ \\
$A C D(n=12)$ & $6 / 6$ & $24.17 \pm 1.19$ \\
AR+ACD $(n=15)$ & $6 / 9$ & $26.53 \pm 1.32$ \\
\hline
\end{tabular}

control for each of the allergens tested was considered as a positive response. The results were listed in Table 2 .

The epicutaneous patch (manufactured by Rainmix Biotechnology, Anhui, China) tests were performed on the upper back and evaluated after 48 and $72 \mathrm{~h}$. The test reactions were graded from no reaction to grade,+++ , and +++ , depending on the intensity of the reaction following the recommendations of the International Contact Dermatitis Research Group [21]. The results were listed in Table 3.

\section{Flow cytometry}

For surface marker labeling, $50 \mu \mathrm{l}$ EDTA anticoagulated blood of each sample was incubated with fluorochromeconjugated antibodies for $20 \mathrm{~min}$ in dark. After that, $450 \mu \mathrm{l}$ OptiLyse C (Beckman Coulter, USA) was added for erythrocytes lysis. Following $10 \mathrm{~min}$ incubation in dark, $50 \mu \mathrm{l}$ absolute count beads (Biolegend, USA) were added before events of stained cells were acquired with a FACS CantolI flow cytometer (BD Biosciences, USA).

For intracellular labeling, PBMCs were isolated with Ficoll-Hypaque density gradients. After centrifuging at $1000 \mathrm{~g}$ for $20 \mathrm{~min}$ at room temperature, the interphase cell layer was carefully transferred into a $15 \mathrm{ml}$ tube. The cell pellet was washed with $10 \mathrm{ml}$ PBS containing $5 \% \mathrm{FBS}$ and centrifuged at $600 \mathrm{~g}$ for $5 \mathrm{~min}$. For cytokine detection, $2 \times 10^{6}$ cells of each sample were cultured in 10\% FBS RPMI-1640 medium (Gibco, USA) with $50 \mathrm{ng} /$ $\mathrm{ml}$ of PAM (Sigma, USA), $1 \mu \mathrm{g} / \mathrm{ml}$ Ionomycin (Yeason, China) in the presence of $1 \mu \mathrm{g} / \mathrm{ml}$ Brefeldin A (Yeason, China) at $37{ }^{\circ} \mathrm{C}$ cell incubator with $5 \% \mathrm{CO}_{2}$. Then cells were permeabilized using Fixation/Permeabilization Solution Kit (BD Biosciences, USA) according to the manufacturer's protocol after surface marker labeling. Cell events were acquired with FACS CantolI flow cytometer (BD Biosciences, USA) and data were analyzed with FlowJo (v10, Tree Star). Following antibodies were used: For surface marker labeling: CD3 APC-H7, CD4 BV421, CD8 APC-R700, CD19 PE-Cy7, CD16 V500, CD56 PerCP-Cy5.5, CD45RA APC, CD45RO FITC. For

Table 2 Results of skin prick tests

\begin{tabular}{|c|c|c|c|c|c|}
\hline \multirow[t]{2}{*}{ Allergen } & & \multicolumn{4}{|c|}{ Positive (n, \%) } \\
\hline & & $\mathrm{HC}(\mathrm{n}=28)$ & $A R(n=30)$ & $A R+A C D(n=15)$ & $A C D(n=12)$ \\
\hline \multirow[t]{2}{*}{ Mite } & D. pteronyssionus & 0 & $11,36.7 \%$ & $7,50 \%$ & 0 \\
\hline & D. farinae & 0 & $11,36.7 \%$ & $7,50 \%$ & 0 \\
\hline \multirow[t]{2}{*}{ Trees pollen } & Common silver birch & 0 & $4,13.3 \%$ & $2,13.3 \%$ & 0 \\
\hline & Mountain juniper & 0 & $18,50 \%$ & $7,50 \%$ & 0 \\
\hline \multirow[t]{2}{*}{ Weeds pollen } & Mugwort & 0 & $2,6.7 \%$ & $3,20 \%$ & 0 \\
\hline & Japanese Hop & 0 & $5,16.7 \%$ & $4,26.7 \%$ & 0 \\
\hline
\end{tabular}


Table 3 Results of epicutaneous patch tests

\begin{tabular}{lllll}
\hline Allergen $^{\text {a }}$ & Positive $(\mathbf{n}, \%)$ & & \\
\cline { 2 - 5 } & HC (n= 28) & AR (n= 30) & ACD (n= 12) & AR + ACD (n= 15) \\
\hline Potassium dichromate & 0 & 0 & $3,25 \%$ & $2,13.3 \%$ \\
Ursol & 0 & 0 & $5,41.7 \%$ & $5,33.3 \%$ \\
Paraben mix & 0 & 0 & $3,25 \%$ & 0 \\
Cobalt chloride & 0 & 0 & $3,25 \%$ & $1,6.7 \%$ \\
Nickel sulfate & 0 & 0 & $1,8.3 \%$ & $4,26.7 \%$ \\
Colophony & 0 & 0 & $1,8.3 \%$ & $1,6.7 \%$ \\
Fragrance mix & 0 & 0 & 0 & $2,13.3 \%$ \\
Thiomersalate & 0 & 0 & 0 & $2,13.3 \%$ \\
Quaterium-15 & 0 & 0 & 0 & $3,20 \%$ \\
P-tert-butyl phenol formaldehyde & 0 & 0 & 0 & $1,6.7 \%$ \\
resin & & & &
\end{tabular}

${ }^{a}$ Kathon CG, formaldehyde, bronopol, quadrol, mercaptobenzothiazole, carba mix, rubber mix, $\mathrm{N}$-cyclohexylthiopeptide lipid, quinol and epoxy resin are not listed in the table on account of none of the subjects showed positive reaction for these allergens

intracellular labeling: CD4 PerCP-Cy5.5, CD8 PE-Cy7, IL-4 PE, IFN- $\gamma$ APC, granzyme B FITC. All antibodies were purchased from BioLegend.

\section{Measurement of serum cytokines}

According to the manufacturer's instructions of the Human Cytokine/Chemokine Panel MILLIPLEX ${ }^{\circledR}$ MAP kits (Cat. No. HCYTOMAG-60K: IFN- $\gamma$, IFN- $\alpha 2$, IL-1 $\beta$, IL-1 $\alpha$, IL-8, IL-4, IL-6, IL-10, IL-12(p70), IL-15, IL-17A, TNF- $\alpha$ ) (Merck Millipore, Germany), serum concentrations of multiple cytokines were measured by a Luminex200 platform (Merck Millipore, Germany). In brief, the plate was pretreated with $200 \mu \mathrm{l}$ wash buffer for10 min. Next, $25 \mu \mathrm{l}$ serum of each sample, $25 \mu \mathrm{l}$ assay buffer and $25 \mu \mathrm{l}$ mixed beads were added to sample wells. The background wells, QC wells and standard wells were added with corresponding reagents following the instructions. The plate was sealed and incubated with shaking at $4{ }^{\circ} \mathrm{C}$ overnight. The next day, the plate was washed twice with wash buffer and $25 \mu$ l detection antibodies were added for a $1 \mathrm{~h}$ incubation at room temperature. After washed twice with wash buffer, each well was incubated with $25 \mu$ l Streptavidin Phycoerythrin for $30 \mathrm{~min}$. After two wash steps, $150 \mu \mathrm{l}$ sheath fluid was added and the data were collected by the Luminex 200 platform. All samples were measured in duplicate.

\section{Measurement of serum immunoglobulin, IgG4, C3, C4 and autoantibodies}

Serum IgG, IgA, IgM and C3, C4 were measured by immunoturbidimetry using an automated Beckman Image 800 Immunochemistry System (Beckman Coulter, USA) according to the manufacturer's instructions. Serum IgE was measured by ELISA using EUROIMMUN
Analyzer I (Euroimmun, Germany) according to the manufacturer's instructions. Serum IgG4 was measured by ELISA (SAB, USA). Serum autoantibodies (nRNP, Sm, SS-A, Ro-52, SS-B, Scl-70, PM-Scl, Jo-1, CENP B, PCNA, dsDNA, NUCL, Histones, rib-P, AMA-M2) were measured by EUROBlotMater and the data were analyzed by EUROBlotCamera (Euroimmun, Germany).

\section{Statistical analysis}

The scatter plots data were represented as the mean \pm SEM. Statistical analyses were performed using one-way ANOVA and Tukey's multiple comparisons test or two-tailed Student $t$-tests (unpaired) in Prism 7.0 (GraphPad Software, USA). Significant differences between groups were represented by ${ }^{*} p<0.05$, *** $p<0.01$, and **** $p<0.001$.

\section{Results}

Differential levels of serum immunoglobulins and cytokines in AR or/and ACD patients

A total of 57 patients diagnosed with AR or/ and ACD aged from 19 to 35 years were included in the study. AR combined with ACD patients were defined as the AR + ACD group. Results for skin prick tests and epicutaneous patch tests were listed in Tables 2 and 3. As expected, all healthy volunteers showed no reaction in response to these allergens.

We firstly investigated the serum levels of immunoglobulin and complement C3, C4. IgE played a key role in type I hypersensitivity mediating various atopic diseases [22]. Indeed, the results showed levels of IgE were elevated in all three patient groups (Fig. 1A). Interestingly, compared with those in $\mathrm{HCs}$, IgA, IgG and IgG4, one of the subclasses of IgG, were elevated in 

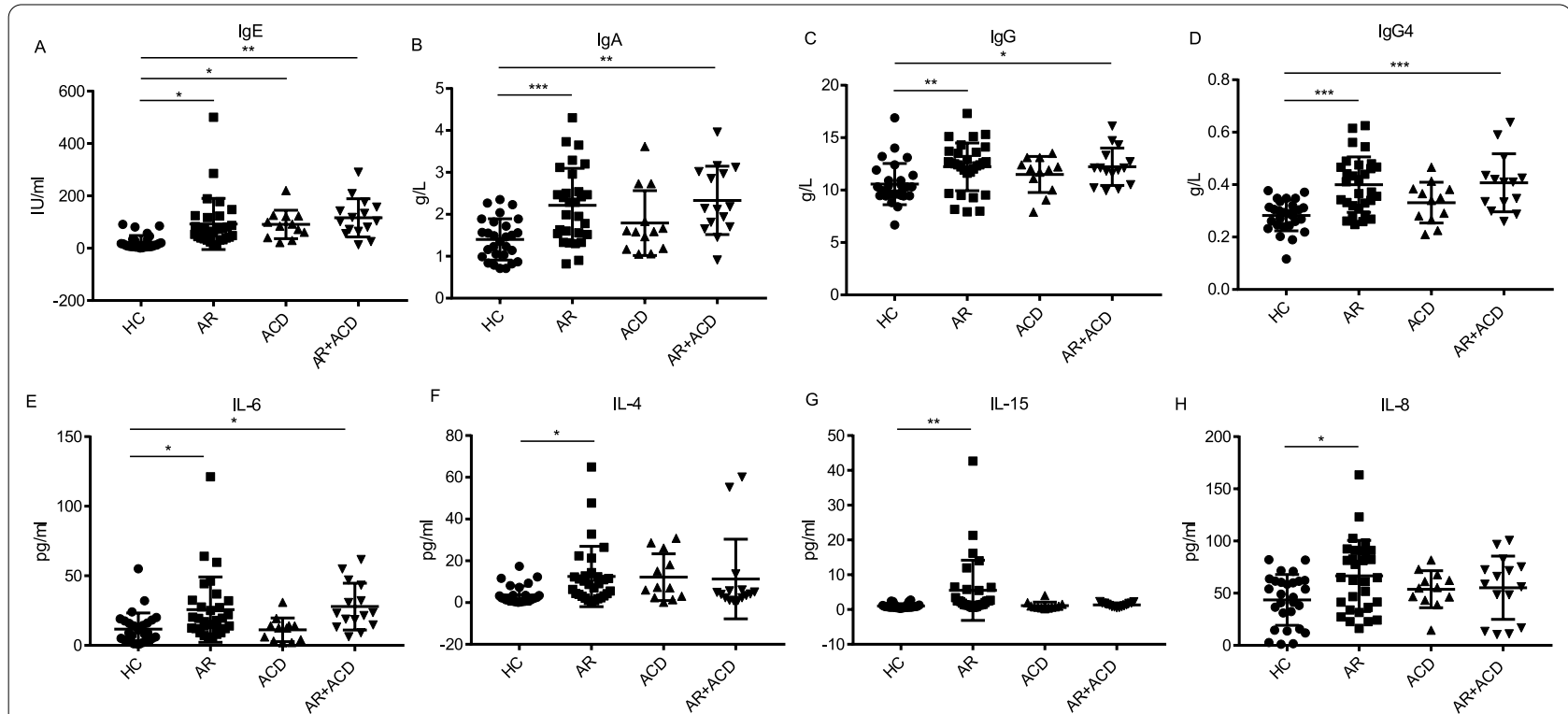

Fig. 1 The serum levels of $\lg E, \lg A$, IgG, IgG4, IL-6, IL-4, IL-15 and IL-8. A-D The serum levels of IgE and IgG4 were measured by ELISA, and IgA and IgG measured by immunoturbidimetry. E-H The concentrations of IL-6, IL-4, IL-15 and IL-8 were determined by the Luminex200 platform. HC, healthy controls, $n=28 ; A R$, allergic rhinitis, $n=30 ; A C D$, allergic contact dermatitis, $n=12 ; A R+A C D$, allergic rhinitis combined with allergic contact dermatitis, $n=15 .^{*} p<0.05,{ }^{* *} p<0.01$, and ${ }^{* * *} p<0.001$ (one-way ANOVA and Tukey's multiple comparisons test)

AR group and AR + ACD group, but not in ACD group (Fig. 1B-D). It implied that the IgG and IgA levels were disturbed in AR patients but not in patients afflicted with ACD only. By contrast, the serum IgM and complement C3, C4 were all at comparable levels to controls (Additional file 1: Fig S1A-C).

Next, we examined the levels of serum cytokines (IFN- $\gamma$, IFN- $\alpha 2$, IL-1 $\beta$, IL- $1 \alpha$, IL- 8 , IL-4, IL-6, IL-10, IL-12(p70), IL-15, IL-17A, TNF- $\alpha$ ) in each group by Luminex200 platform. Our data revealed that serum IL-6 remarkably increased in both AR group and AR + ACD group, compared to that in HCs (Fig. 1E). Surprisingly, IL-4, IL-15 and IL-8, three important pro-inflammatory cytokines that involved in Th2 response were found elevated in patients with AR only (Fig. 1D-F), but not in $A R+A C D$ group and $A C D$ group (Fig. $1 F-H)$. Other cytokines were not found to have any difference among different groups (Additional file 1: Fig S1C-J).

\section{Lymphocytes subsets in the peripheral blood of patients with AR or/and ACD}

In parallel, the lymphocytes subsets in peripheral blood from indicated groups were investigated. Representative FACS plots of the $\mathrm{HC}$ group and gating strategy were shown (Fig. 2A). Compared with HC group, the percentage of lymphocytes was decreased in AR group (Fig. 2B). While $\mathrm{CD} 4+\mathrm{CD} 3+\mathrm{T}$ cells did not show a significant change, an increase in $\mathrm{CD} 8+\mathrm{CD} 3+\mathrm{T}$ cells was observed in AR group, but not in ACD group or
$\mathrm{AR}+\mathrm{ACD}$ group (Fig. 2C, D). As a result, CD4/CD8 ratio was decreased in AR group (Fig. 2E). There was no significant difference observed in $\mathrm{CD} 19+\mathrm{B}$ cells and CD3-CD56+CD16+NK cells among four groups (Additional file 1: Fig S2A, B).

Considering that memory $\mathrm{T}$ cells have been observed playing a role in allergic responses [23], we examined the proportion of memory/naive $\mathrm{T}$ cell subsets in different patient groups and HCs. An increased proportion of CD45RO + CD45RA-memory CD4+ $\mathrm{T}$ cells were observed in AR group (Fig. 2F). Whereas, AR + ACD group presented with an elevated proportion of $\mathrm{CD} 45 \mathrm{RO}+\mathrm{CD} 45 \mathrm{RA}$-memory $\mathrm{CD} 8+\mathrm{T}$ cells (Fig. 2G). The immune cell compartments in patients with ACD only were minimally disturbed. Neither memory $\mathrm{CD} 4+$ nor memory $\mathrm{CD} 8+\mathrm{T}$ cells had any ratio change in ACD patients compared to HCs (Fig. 2F, G).

In sum, AR patients showed the most intense impact on the immune components reflected by an elevation of various serum cytokines (IL-4, IL-15, IL-8, IL-6) as well as a reduced $\mathrm{CD} 4 / 8$ ratio in addition to an augmented memory CD4+T-cell compartment in the peripheral circulation. AR + ACD group was featured with a moderate change in serum cytokines (increased in IL6 expression only) and an increased ratio in peripheral memory $\mathrm{CD} 8+\mathrm{T}$ cells. Based on our data, it was perceivable that cytokines and T-cell compartment in patients with ACD only were least affected in comparison with other allergic conditions. 


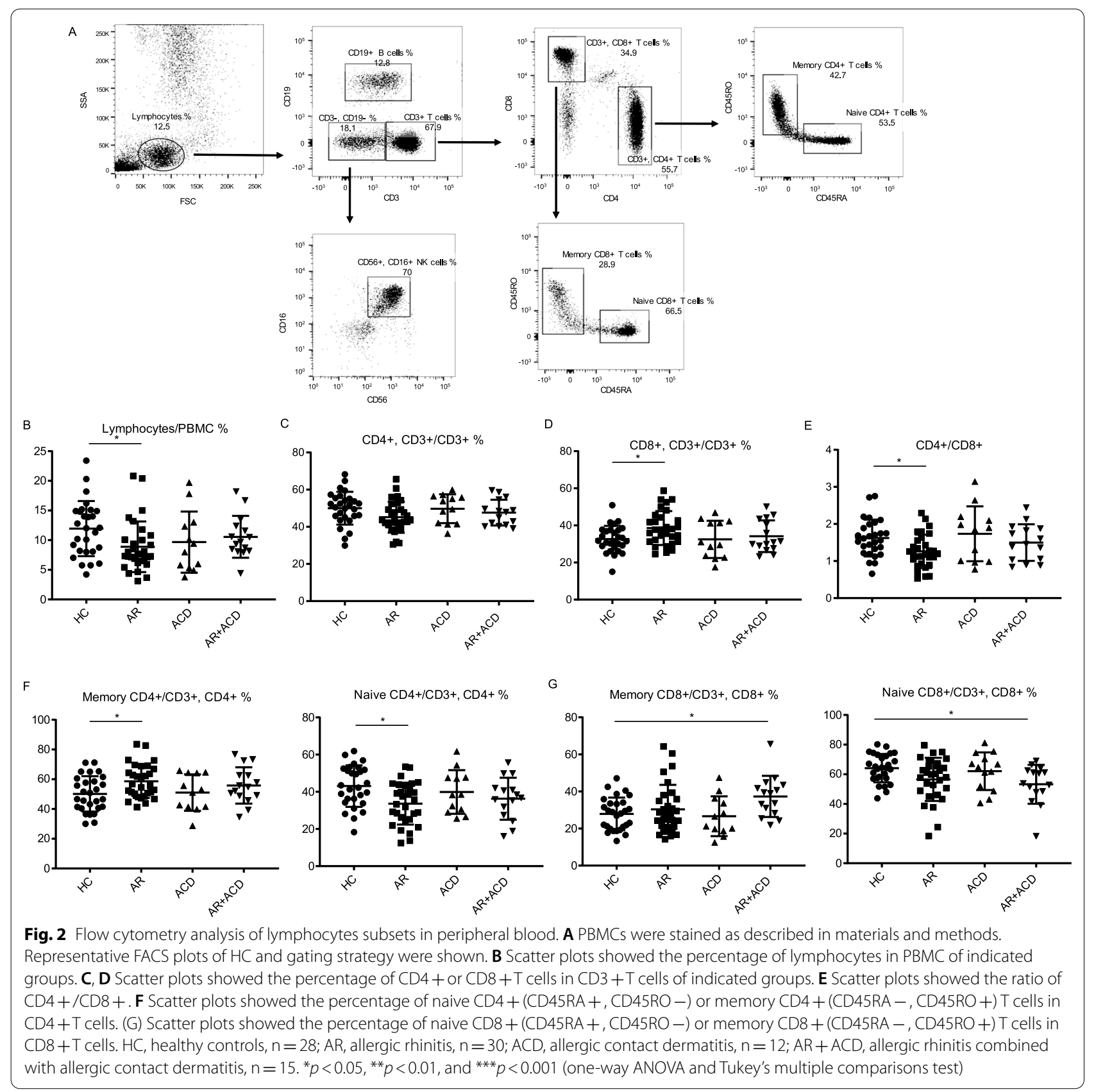

Decreased IFN- $\gamma+$ CD4 + /IL-4 + CD4 + cells and increased granzyme $B+C D 8+T$ cells in AR patients

To dissect the T-cell function in these patient groups, intracellular staining for Th1-related cytokine (IFN- $\gamma$ ), Th2-related cytokine (IL-4) and lytic granule (granzyme B) in T-cell subsets were performed. A reduction of IFN- $\gamma+\mathrm{CD} 4+$ subset was observed in AR group (Fig. 3A). Although there was no significant change in the IL- $4+$ CD $4+$ subset, the ratio of IFN- $\gamma+\mathrm{CD} 4+($ Th1 $) /$ $\mathrm{IL}-4+\mathrm{CD} 4+(\mathrm{Th} 2)$ showed a decrease in AR group
(Fig. 3B, C). Moreover, the proportion of granzyme $\mathrm{B}+\mathrm{CD} 8+\mathrm{T}$ cells was increased while IFN $-\gamma+\mathrm{CD} 8+\mathrm{T}$ cells showed no change (Fig. 3D, E). It indicated the imbalance of Th1/Th2 and the activation of CD $8+\mathrm{T}$ cells in AR group.

\section{Higher incidence and broader spectrum of autoantibodies in AR + ACD patients}

Previous research has established that autoantibodies were involved in the pathogenesis of autoimmune 


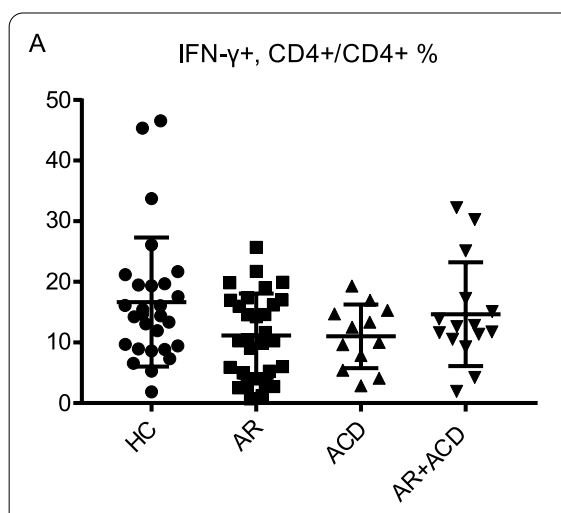

D

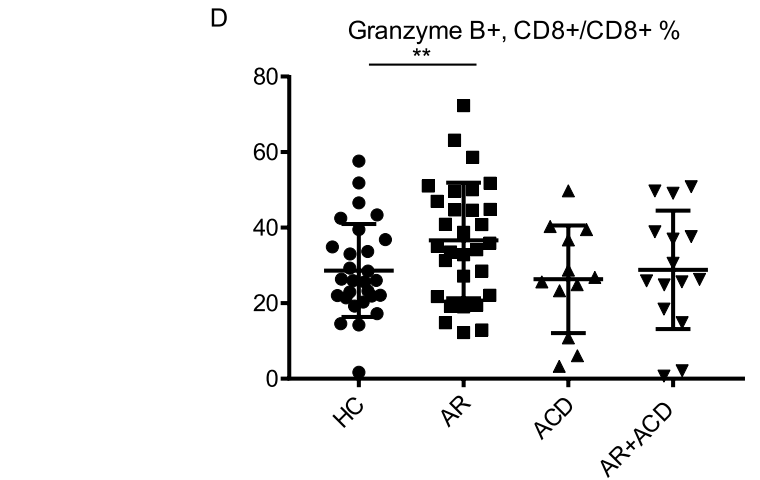

B

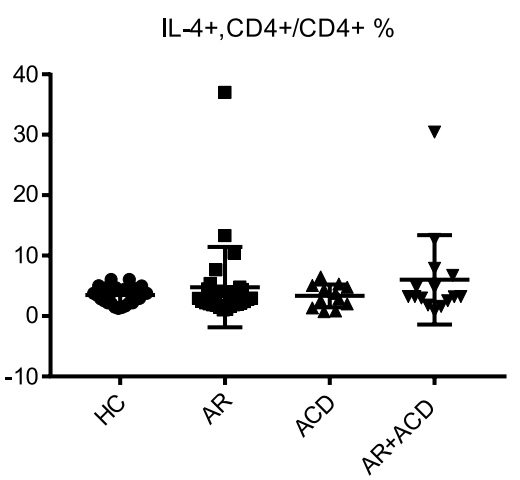

E
C

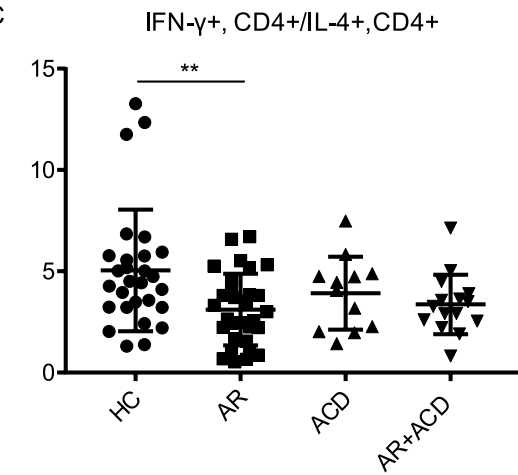

IFN- - +, CD $8+/ C D 8 \%$

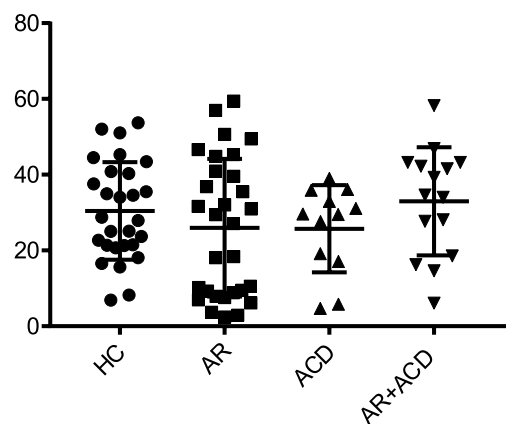

Fig. 3 The ratio of IFN- $\gamma+C D 4+/ L-4+C D 4+$ was decreased and the proportion of granzyme $B+C D 8+T$ cells was increased in AR patients. A-E Intracellular cytokine staining was carried out following PMA $(50 \mathrm{ng} / \mathrm{ml})$ and ionomycin $(1 \mu \mathrm{g} / \mathrm{ml})$ stimulation for 5 h. Scatter plots showed the percentage of IFN- $\gamma+\mathrm{CD} 4+$, IL-4 + CD4 +, the ratio of IFN- $\gamma+\mathrm{CD} 4+/ \mathrm{LL}-4+\mathrm{CD} 4+$, granzyme B + CD8 + and IFN- $\gamma+\mathrm{CD} 8+$. HC, healthy controls, $n=28 ; A R$, allergic rhinitis, $n=30 ; A C D$, allergic contact dermatitis, $n=12 ; A R+A C D$, allergic rhinitis combined with allergic contact dermatitis, $\mathrm{n}=15 .{ }^{*} p<0.05,{ }^{* *} p<0.01$, and ${ }^{* * *} p<0.001$ (one-way ANOVA and Tukey's multiple comparisons test)

diseases [24]. To investigate if the long-term allergic conditions could trigger autoimmunity leading to the production of autoantibodies, we characterized the profile of autoantibodies (IgG) (nRNP, Sm, SS-A, Ro-52, SS-B, Scl-70, PM-Scl, Jo-1, CENP B, PCNA, dsDNA, NUCL, Histones, rib-P, AMA-M2) in the serum of patients. We defined "autoantibody (IgG) positive rate" as the percentage of positive individuals in each group. When a patient showed one or more autoantibody reactivity in the autoantibody profile test, he or she was defined as an autoantibody-positive individual.

The results showed that the autoantibody positive rate in AR and ACD groups was $26.7 \%$ and $25 \%$, respectively (Fig. 4A). Strikingly, in the AR+ACD group, the positive rate was increased to $53.3 \%$, which implied the additive effect of AR and ACD towards autoimmunity (Fig. 4A). As shown in Fig. 4B illustrating the profile of autoantibodies presentation, several patients showed multiple autoantibody specificities. It appeared that the histones IgG was the prevalent autoantibodies in AR patients (Fig. 4B). Moreover, AR + ACD group presented with a more diversified autoantibody spectrum (Fig. 4B).
In other words, AR group had a histones autoantibody bias, and AR + ACD group possessed a higher positive rate and a broader spectrum of autoantibodies. Taking together, these results suggested an association of autoimmune propensity with these allergic diseases to various extents.

\section{Different immunoglobulin levels, cytokines expression and T-cell subsets between PAR and SAR patients}

Considering AR group exhibited significant differences in several cytokines and T-cell subsets compared with HC group, a more detailed analysis was made. AR patients were divided into SAR $(n=27)$ or PAR $(n=16)$ depending on the reactivity of skin prick tests to cyclic pollens or year-round allergens (mite) (Table 2). Two patients exhibiting positive reactions to both cyclic pollens and mite were excluded. Data segregation for AR patients revealed that total serum IgA and IgE levels were elevated in both SAR and PAR patients, while total IgG level was only increased in SAR patients (Fig. 5AC). Cytokine analysis showed an increase of IL-4 and IL-15 in the SAR patients, while IL-6 and IL- 8 were 

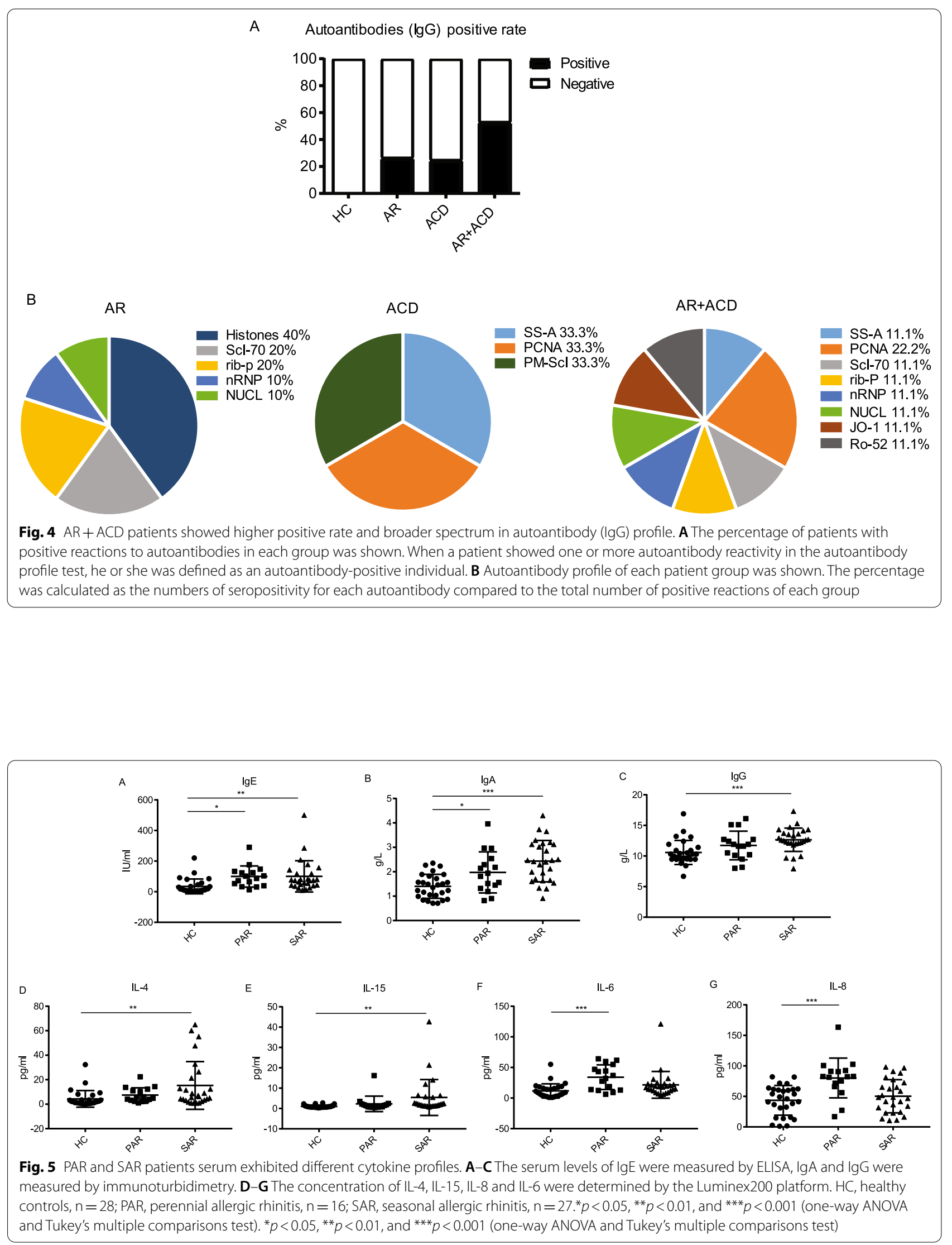
elevated in PAR patients (Fig. 5D-G). In T-cell subsets analysis, CD4/CD8 ratio was decreased in SAR patients, although no significant change in $\mathrm{CD} 4+\mathrm{CD} 3+\mathrm{T}$ cells or $\mathrm{CD} 8+\mathrm{CD} 3+\mathrm{T}$ cells was observed (Fig. 6A-C). Similarly, compared with the HC group, only SAR patients showed a significant increase of memory/naive ratio in both CD4+and CD8+ T cells (Fig. 6D, E). In sum, the results suggested that SAR and PAR are two distinguishable allergic conditions with multiple immune elements presenting at different levels.

\section{Discussion}

In this study, we investigated the immune responses in peripheral blood from AR, ACD and AR combined with ACD patients, including serum levels of immunoglobulin, cytokines, the proportion of lymphocytes subsets, as well as autoantibody profile. It expanded our understanding on the pathogenesis of allergic disease and clarified the different characteristics of immune responses among patients diagnosed with AR or/and ACD.

In the serological examination, $A R$ patients and AR + ACD patients exhibited an elevated level of IgE, IgG and IgA compared with the HC group, while patients with ACD only showed an increase in IgE level but not IgA and IgG. There is consensus that antigen-specific $\mathrm{IgE}$ is crucial for the development of these allergic disorders $[25,26]$. Contradicted to the belief that IgE is not an important mediator in ACD, the increased IgE in patients with $A C D$ might be a sequela from a vicious circle of sensitization to other allergens due to repeated skin barrier disruption [27]. During the late phase of allergic process, IgE is released and binds to high-affinity receptor FceRI on the surface of mast cells and basophils $[10,26]$. Following allergens binding to allergen-specific IgE, a complex cascade of mediators releasing is triggered $[10,26]$. By contrast, allergen-specific IgG, which is also induced by allergen, can downregulate IgE-mediated anaphylaxis by masking allergens and crosslinking with FceRI and FcyRIIb $[28,29]$. On the other hand, IgG could induce an allergic process by activating Fc $\mathrm{R} R$ s on different cell types when allergen levels are high [30]. The elevation of serum IgG was also found in the mouse model of AR disease [31], besides, the nasal IgG was higher in AR patients compared with healthy controls [32]. There are four subclasses of IgG (IgG1, IgG2, IgG3 and IgG4). The inhaled allergens were strongly associated with serum IgG4 response [33]. Production of IgG4 in allergenspecific immunotherapy (AIT) is an immunological hallmark for successful tolerance establishment [34]. During AIT, AR patients showed a higher increase in serum IgG4 compared to patients with asthma symptoms [35]. Similarly, previous studies found a higher IgG4 level in nasal secretion and serum of AR patients [36, 37]. The fact that IgG4, an immunosuppressive mediator, increased in AR and AR + ACD patients implied that a complex negotiation between allergic inflammation and

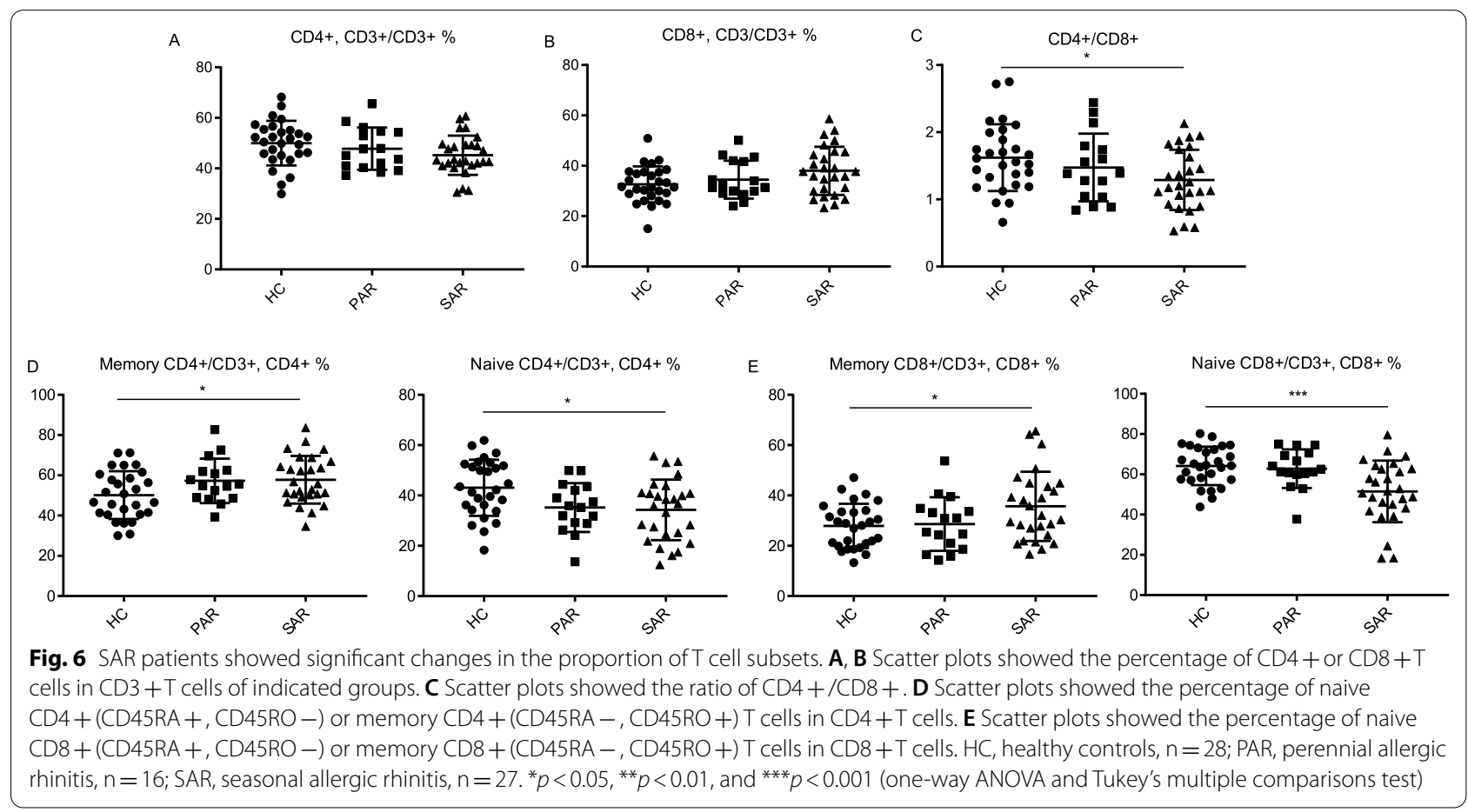


tolerance was established in these patients. IgA mainly occurs as a monomer form in serum, and it is found as secretory IgA in secretion [38]. It has been reported that the salivary and nasal but not serum IgA levels were increased in AR patients $[39,40]$. Deficiency in IgA may cause a change in the mucosal defense preceding the onset of allergy [41]. Other studies reported that a high level of IgA may be associated with mitigation of allergic symptoms, while other data indicated that allergicspecific IgA induced eosinophil degranulation [42-44]. The role of IgA in allergic disorders remains unclear. Our results found remarkably increased IgG and IgA levels in $A R$ and $A R+A C D$ patients, but not in the ACD patients. Based on our multiple measurements on immunological elements, we boldly believe that AR has a much intensive impact on systemic immunity while ACD's influence is more locally constrained.

In cytokines/chemokines determination, AR patients expressed elevated levels of IL-4, IL-15, IL-8 and IL-6, while AR + ACD patients only showed an increase in IL-6. However, patients with ACD did not show any significant change in these cytokines. IL-4 is a characteristic Th2 cytokine critical for IgE-mediated inflammatory response [45]. IL-6 is a typical pro-inflammatory cytokine [11, 12]. IL- 8 is a chemotactic cytokine for neutrophils and primed eosinophils [46]. IL-15 has been reported to be induced by allergen-specific Th2 cells [47]. It plays important roles in $\mathrm{T}$ cell activation and homeostasis, survival of $\mathrm{B}$ cells, mast cells and eosinophils [48, 49]. Meanwhile, it has been documented that in the nasal lavage fluid of AR patients, the expression of IL- 4 and IL- 6 increased $[50,51]$. Additionally, there is evidence showing that IL-15 prevents AR through the reactivation of antigenspecific CD8 + cells [52]. Likewise, in a context of a more intensive impact on system immunity in AR versus the other two allergic conditions, multiple cytokine changes were found only in AR patients. ACD or comorbidity of $A R$ and ACD seemed a different disease entity from AR based on the cytokine expression profile. Increased IL-6 in AR + ACD patients is possibly an intermediate responder along with the allergy march from $A C D$ to $\mathrm{ACD}+\mathrm{AR}$. This conjecture was consolidated by the fact that increased IL-6 in AR mainly occurred in PAR patients, a condition with milder inflammation than SAR $[53,54]$. Why PAR patients are the major contributors to IL-8 elevation in the AR group is hard to explain. Our impression is that PAR patients retained a chronic inflammation rather than an acute response in SAR due to their long-term allergen exposure.

The presence of autoantibodies in serum reflects leakiness of central and/or peripheral tolerance and may lead to the manifestation of autoimmune diseases
[24]. A plethora of evidence has suggested that serum autoantibodies participate in the progress of allergic diseases $[55,56]$. We confirmed that a higher incidence of AR patients presented with autoantibodies in blood samples, with histones as the prevalent antigen, which is congruent with previous studies in animal models [55]. Worth to mention, AR +ACD patients showed higher incidence and more diversified autoantibodies than patients with sole AR or sole ACD. It suggested that comorbidity of AR and ACD poses the patient higher risk for autoimmune disorders.

In lymphocytes subsets analysis, a significant decrease of $\mathrm{CD} 4+/ \mathrm{CD} 8+$ ratio in $\mathrm{AR}$ patients was observed. Several previous studies showed no significant difference in CD4+ T cells in AR patients, but some others found increased $\mathrm{CD} 4+\mathrm{T}$ cells [57-59]. It might own to different allergens or the severity of the disease. Allergic inflammation is mainly driven by Th2 cells [9]. IL-4 is a typical Th2-cytokine, and IFN- $\gamma$ can be produced by Th1 cells [60]. We found a decrease in IFN- $\gamma+\mathrm{CD} 4+1$ IL-4+CD4+ ratio in AR patients, which indicated the imbalance of Th1/Th2 in AR. Besides, AR patients showed an increase in memory $\mathrm{CD} 4+\mathrm{T}$ cells and a decrease in naïve $\mathrm{CD} 4+\mathrm{T}$ cells, while $\mathrm{AR}+\mathrm{ACD}$ patients showed similar changes in CD8 $+\mathrm{T}$ cell subsets. The allergic condition lead to the formation of a pool of memory allergen [19], while AR and AR + ACD had different preferences in the induction of $\mathrm{CD} 4+$ and $\mathrm{CD} 8+\mathrm{T}$ cells. Moreover, SAR patients exhibited significant changes in memory/naïve subsets of both $\mathrm{CD} 4+$ and CD8 + T cells while this was not true for PAR patients. It might be a result from a more pronounced allergenicity in cyclic pollens SAR patients encountered.

\section{Conclusions}

In conclusion, our study characterized the immune responses in AR, ACD and AR combined with ACD. AR patients showed elevated serum levels of IgE, IgA, IgG, IgG4, as well as IL-4, IL-15, IL-8 and IL-6. Furthermore, IL-4 and IL-6 were elevated in SAR patients, while IL- 6 and IL- 8 were elevated in PAR patients, which hinted the different tendencies of immune responses. What's more, AR disease caused a decreased CD4/ $\mathrm{CD} 8$ ratio and an imbalance in $\mathrm{T}$ cell subsets, including the increased proportion of memory $\mathrm{CD} 4+\mathrm{T}$ cells, skewed Th2 response, and enhanced $\mathrm{CD} 8+\mathrm{T}$ cells activation. SAR but not PAR caused intense changes in $\mathrm{T}$ cell subsets. Despite not intensifying the immune responses, comorbidity of AR with ACD presented with an increased proportion of memory CD $8+\mathrm{T}$ cells and an increased propensity for autoimmune disorders. 


\section{Abbreviations}

AR: Allergic rhinitis; ACD: Allergic contact dermatitis; Ig: Immunoglobulin; PBMC: Peripheral blood mononuclear cells; IL: Interleukin; IFN- $\gamma$ : Interferon- $\gamma$; ANOVA test: Analysis of variance test.

\section{Supplementary Information}

The online version contains supplementary material available at https://doi. org/10.1186/s13223-022-00646-6.

Additional file 1: Fig. S1. The serum levels of IgM, C3, C4 and cytokines. Fig. S2. Flow cytometry analysis of B cell and NK cell subsets in peripheral blood.

\section{Acknowledgements}

The authors thank the patients and volunteers for their participation in this study.

\section{Author's contributions}

WC performed experiments, analyzed data, and wrote the manuscript; $X Z$, $M L, Z C$ and XW performed experiments and analyzed data; CW, AC and CW participated in the experiments; HW, HY and JG designed, conceived, and supervised the study and wrote the manuscript. All authors read and approved the final manuscript.

\section{Funding}

This work was supported by grants from a startup research fund to J.G from Beijing Children's Hospital, a teaching hospital affiliated to Capital Medical University, Clinical Research Supporting Fund of the Third Medical Center of Chinese PLA General Hospital (wz2017007) and Beijing Natural Science Foundation Program (7204259).

\section{Availability of data and materials}

The datasets used and/or analyzed during the current study are available from the corresponding author on reasonable request.

\section{Declarations}

Ethics approval and consent to participate

The study was conducted with approval from the Medical Ethics Committee of Third Medical Center of Chinese PLA General Hospital and Inner Mongolia Xilinguo League Central Hospital. Informed consent was obtained from all subjects in accordance with the Declaration of Helsinki, and each subject provided written informed.

\section{Consent for publication}

All patients' parents/guardians provided written informed consent for the publication of information resulting from the results without any personally identifying information.

\section{Competing interests}

The authors declare that they have no competing interests.

\section{Author details}

${ }^{1}$ Laboratory of Tumor Immunology, Beijing Pediatric Research Institute, Beijing Children's Hospital, Capital Medical University, National Center for Children's Health, Beijing 100045, China. ${ }^{2}$ Key Laboratory of Major Diseases in Children, Ministry of Education, Beijing Pediatric Research Institute, Beijing Children's Hospital, Capital Medical University, National Center for Children's Health, Beijing 100045, China. ${ }^{3}$ Third Medical Center of Chinese, PLA General Hospital, Beijing 100000, China. ${ }^{4}$ Department of Allergy, Inner Mongolia Xilinguo League Central Hospital, Xilinhot 026000, China.

Received: 8 September 2021 Accepted: 6 January 2022

Published online: 11 February 2022

\section{References}

1. Bousquet J, Anto JM, Bachert C, Baiardini I, Bosnic-Anticevich S, Walter CG, et al. Allergic rhinitis. Nat Rev Dis Primers. 2020;6(1):95.

2. Nassau S, Fonacier L. Allergic contact dermatitis. Med Clin North Am. 2020;104(1):61-76

3. Nosbaum A, Vocanson M, Rozieres A, Hennino A, Nicolas JF. Allergic and irritant contact dermatitis. Eur J Dermatol. 2009:19(4):325-32.

4. Rashid RS, Shim TN. Contact dermatitis. BMJ. 2016;353:i3299.

5. Brozek JL, Bousquet J, Agache I, Agarwal A, Bachert C, Bosnic-Anticevich $\mathrm{S}$, et al. Allergic rhinitis and its impact on asthma (ARIA) guidelines-2016 revision. J Allergy Clin Immunol. 2017;140(4):950-8.

6. Kakli HA, Riley TD. Allergic rhinitis. Prim Care. 2016;43(3):465-75.

7. Ozdoganoglu T, Songu M. The burden of allergic rhinitis and asthma. Ther Adv Respir Dis. 2012;6(1):11-23.

8. Greiner AN, Hellings PW, Rotiroti G, Scadding GK. Allergic rhinitis. Lancet. 2011:378(9809):2112-22.

9. Bernstein DI, Schwartz G, Bernstein JA. Allergic rhinitis: mechanisms and treatment. Immunol Allergy Clin North Am. 2016;36(2):261-78.

10. Galli SJ, Tsai M. IgE and mast cells in allergic disease. Nat Med. 2012;18(5):693-704

11. Geha RS, Jabara HH, Brodeur SR. The regulation of immunoglobulin $E$ class-switch recombination. Nat Rev Immunol. 2003;3(9):721-32.

12. Gauchat JF, Henchoz S, Mazzei G, Aubry JP, Brunner T, Blasey H, et al. Induction of human IgE synthesis in B cells by mast cells and basophils. Nature. 1993;365(6444):340-3.

13. Fireman P. Cytokines and allergic rhinitis. Allergy Asthma Proc. 1996:17(4):175-8.

14. Verschoor D, von Gunten S. Allergy and atopic diseases: an update on experimental evidence. Int Arch Allergy Immunol. 2019;180(4):235-43.

15. Botturi K, Lacoeuille Y, Cavailles A, Vervloet D, Magnan A. Differences in allergen-induced $T$ cell activation between allergic asthma and rhinitis: role of CD28, ICOS and CTLA-4. Respir Res. 2011;12:25.

16. Van Overtvelt L, Wambre E, Maillere B, von Hofe E, Louise A, Balazuc AM, et al. Assessment of Bet $v$ 1-specific CD4+ T cell responses in allergic and nonallergic individuals using MHC class II peptide tetramers. J Immunol. 2008;180(7):4514-22

17. Zhang LX, Liu T. Treg influences the pathogenesis of allergic rhinitis through TICAM-1 pathway. Lin Chung Er Bi Yan Hou Tou Jing Wai Ke Za Zhi. 2018;32(22):1763-6.

18. Imbesi S, Minciullo PL, Isola S, Gangemi S. Allergic contact dermatitis: immune system involvement and distinctive clinical cases. Allergol Immunopathol (Madr). 2011:39(6):374-7.

19. Woodfolk JA. T-cell responses to allergens. J Allergy Clin Immunol. 2007;119(2):280-94 (quiz 95-6)

20. Sustiel A, Rocklin R. T cell responses in allergic rhinitis, asthma and atopic dermatitis. Clin Exp Allergy. 1989;19(1):11-8.

21. Pongpairoj K, Ale I, Andersen KE, Bruze M, Diepgen TL, Elsner PU, et al. Proposed ICDRG classification of the clinical presentation of contact allergy. Dermatitis. 2016;27(5):248-58.

22. De Schryver E, Devuyst L, Derycke L, Dullaers M, Van Zele T, Bachert C, et al. Local immunoglobulin $\mathrm{E}$ in the nasal mucosa: clinical implications. Allergy Asthma Immun. 2015;7(4):321-31.

23. Woodfolk JA. T-cell responses to allergens. J Allergy Clin Immun. 2007;119(2):280-94.

24. Ludwig RJ, Vanhoorelbeke K, Leypoldt F, Kaya Z, Bieber K, McLachlan SM, et al. Mechanisms of autoantibody-induced pathology. Front Immunol. 2017:8:603.

25. Zellweger F, Eggel A. IgE-associated allergic disorders: recent advances in etiology, diagnosis, and treatment. Allergy. 2016;71(12):1652-61.

26. Finkelman FD, Khodoun MV, Strait R. Human lgE-independent systemic anaphylaxis. J Allergy Clin Immunol. 2016;137(6):1674-80

27. Galli SJ, Tsai M, Piliponsky AM. The development of allergic inflammation. Nature. 2008;454(7203):445-54.

28. Zhu D, Kepley CL, Zhang M, Zhang K, Saxon A. A novel human immunoglobulin Fc gamma Fc epsilon bifunctional fusion protein inhibits Fc epsilon RI-mediated degranulation. Nat Med. 2002;8(5):518-21.

29. Burton OT, Logsdon SL, Zhou JS, Medina-Tamayo J, Abdel-Gadir A, Noval $\mathrm{RM}$, et al. Oral immunotherapy induces IgG antibodies that act through 
FcgammaRllb to suppress IgE-mediated hypersensitivity. J Allergy Clin Immunol. 2014;134(6):1310-7.

30. Khodoun MV, Strait R, Armstrong L, Yanase N, Finkelman FD. Identification of markers that distinguish lgE-from lgG-mediated anaphylaxis. Proc Natl Acad Sci USA. 2011;108(30):12413-8.

31. Liang KL, Yu SJ, Huang WC, Yen HR. Luteolin attenuates allergic nasal inflammation via inhibition of interleukin-4 in an allergic rhinitis mouse model and peripheral blood from human subjects with allergic rhinitis. Front Pharmacol. 2020;11:291.

32. Benson M, Reinholdt J, Cardell LO. Allergen-reactive antibodies are found in nasal fluids from patients with birch pollen-induced intermittent allergic rhinitis, but not in healthy controls. Allergy. 2003;58(5):386-92.

33. Smoldovskaya O, Feyzkhanova G, Voloshin S, Arefieva A, Chubarova A, Pavlushkina L, et al. Allergen-specific lgE and IgG4 patterns among patients with different allergic diseases. World Allergy Organ J. 2018;11(1):35

34. Okamoto Y, Fujieda S, Okano M, Yoshida Y, Kakudo S, Masuyama K. House dust mite sublingual tablet is effective and safe in patients with allergic rhinitis. Allergy. 2017;72(3):435-43.

35. Lai X, Li J, Xiao X, Liu E, Zhang C, Wang H, et al. Specific lgG4 production during house dust mite immunotherapy among age, gender and allergic disease populations. Int Arch Allergy Immunol. 2013;160(1):37-46.

36. van de Veen W, Akdis M. Role of IgG4 in IgE-mediated allergic responses. J Allergy Clin Immunol. 2016;138(5):1434-5.

37. Miranda DO, Silva DA, Fernandes JF, Queiros MG, Chiba HF, Ynoue $\mathrm{LH}$, et al. Serum and salivary lgE, IgA, and IgG4 antibodies to Dermatophagoides pteronyssinus and its major allergens, Der p1 and Der p2, in allergic and nonallergic children. Clin Dev Immunol. 2011;2011:302739.

38. Hansen IS, Baeten DLP, den Dunnen J. The inflammatory function of human IgA. Cell Mol Life Sci. 2019;76(6):1041-55.

39. Davoodi A, Lotfi R, Mortazavi SH, Gorgin KA, Rezaiemanesh A, Salari F. Retinoic acid correlates with reduced serum IL-10 And TGF-beta in allergic rhinitis. Rep Biochem Mol Biol. 2021;9(4):399-407.

40. Keen C, Johansson S, Reinholdt J, Benson M, Wennergren G. Bet v 1-specific $\lg A$ increases during the pollen season but not after a single allergen challenge in children with birch pollen-induced intermittent allergic rhinitis. Pediatr Allergy Immunol. 2005;16(3):209-16.

41. Schwartz DP, Buckley RH. Serum lgE concentrations and skin reactivity to anti-lgE antibody in IgA-deficient patients. N Engl J Med. 1971;284(10):513-7.

42. Fageras M, Tomicic S, Voor T, Bjorksten B, Jenmalm MC. Slow salivary secretory IgA maturation may relate to low microbial pressure and allergic symptoms in sensitized children. Pediatr Res. 2011;70(6):572-7.

43. Sandin A, Bjorksten B, Bottcher MF, Englund E, Jenmalm MC, Braback L. High salivary secretory $\lg A$ antibody levels are associated with less late-onset wheezing in IgE-sensitized infants. Pediatr Allergy Immunol. 2011;22(5):477-81.

44. Wu LC, Zarrin AA. The production and regulation of IgE by the immune system. Nat Rev Immunol. 2014;14(4):247-59.

45. Bernstein DI, Schwartz G, Bernstein JA. Allergic rhinitis mechanisms and treatment. Immunol Allergy Clin. 2016;36(2):261.

46. Kany S, Vollrath JT, Relja B. Cytokines in inflammatory disease. Int J Mol Sci. 2019;20(23):6008.

47. Carson WE, Ross ME, Baiocchi RA, Marien MJ, Boiani N, Grabstein K, et al. Endogenous production of interleukin 15 by activated human monocytes is critical for optimal production of interferon-gamma by natural killer cells in vitro. J Clin Invest. 1995;96(6):2578-82.

48. Boyman O, Purton JF, Surh CD, Sprent J. Cytokines and T-cell homeostasis. Curr Opin Immunol. 2007;19(3):320-6.

49. Armitage RJ, Macduff BM, Eisenman J, Paxton R, Grabstein KH. IL-15 has stimulatory activity for the induction of $\mathrm{B}$ cell proliferation and differentiation. J Immunol. 1995;154(2):483-90.

50. Baraniuk JN. Pathogenesis of allergic rhinitis. J Allergy Clin Immun. 1997;99(2):S763-72.

51. Kirmaz C, Kirgiz OO, Bayrak P, Yilmaz O, Vatansever S, Ozbilgin K, et al. Effects of allergen-specific immunotherapy on functions of helper and regulatory $T$ cells in patients with seasonal allergic rhinitis. Eur Cytokine Netw. 2011;22(1):15-23.
52. Aoi N, Masuda T, Murakami D, Yajima T, Mizubuchi H, Yamada H, et al. IL-15 prevents allergic rhinitis through reactivation of antigen-specific CD8+ cells. J Allergy Clin Immunol. 2006;117(6):1359-66.

53. van Cauwenberge P, Bachert C, Passalacqua G, Bousquet J, Canonica $\mathrm{G}$, Durham SR, et al. Consensus statement on the treatment of allergic rhinitis. European Academy of Allergology and Clinical Immunology. Allergy. 2000;55(2):116-34.

54. Konig K, Klemens C, Eder K, San NM, Becker S, Kramer MF, et al. Cytokine profiles in nasal fluid of patients with seasonal or persistent allergic rhinitis. Allergy Asthma Clin Immunol. 2015;11(1):26.

55. Nakano T, Kamei R, Fujimura T, Takaoka Y, Hori A, Lai CY, et al. Impact of Histone $\mathrm{H} 1$ on the progression of allergic rhinitis and its suppression by neutralizing antibody in mice. PLoS ONE. 2016;11(4):e0153630.

56. Bozek A, Kolodziejczyk K, Bednarski P. The relationship between autoimmunity and specific immunotherapy for allergic diseases. Hum Vaccin Immunother. 2015;11(12):2764-8

57. Yu X, Wang M, Cao Z. Reduced CD4(+)T cell CXCR3 expression in patients. Front Immunol. 2020;11:581180.

58. Sani MM, Ashari NSM, Abdullah B, Wong KK, Musa KI, Mohamud R, et al. Reduced CD4+ terminally differentiated effector memory T cells in moderate-severe house dust mites sensitized allergic rhinitis patients. Asian Pac J Allergy Immunol. 2019;37(3):138-46.

59. Zhang H, Cardell LO, Bjorkander J, Benson M, Wang H. Comprehensive profiling of peripheral immune cells and subsets in patients with intermittent allergic rhinitis compared to healthy controls and after treatment with glucocorticoids. Inflammation. 2013;36(4):821-9.

60. Mosmann TR, Coffman RL. TH1 and TH2 cells: different patterns of lymphokine secretion lead to different functional properties. Annu Rev Immunol. 1989;7:145-73.

\section{Publisher's Note}

Springer Nature remains neutral with regard to jurisdictional claims in published maps and institutional affiliations.

Ready to submit your research? Choose BMC and benefit from:

- fast, convenient online submission

- thorough peer review by experienced researchers in your field

- rapid publication on acceptance

- support for research data, including large and complex data types

- gold Open Access which fosters wider collaboration and increased citations

- maximum visibility for your research: over $100 \mathrm{M}$ website views per year

At BMC, research is always in progress.

Learn more biomedcentral.com/submissions 